\title{
Caracterização Mineral Na Área Do Sítio Ap Ca 18: Um Estudo De Caso A Partir Do Fenômeno Religioso Presente Às Margens Do Rio Rêgo
}

\author{
Brenda De Cassia Silva Gomes $^{1}$ Ricardo Soares Nogueira ${ }^{2}$ \\ Soraia Campos Carvalho ${ }^{3}$
}

\begin{abstract}
${ }^{1}$ Técnica em Mineração pelo Instituto Federal de Educação, Ciência e Tecnologia do Amapá e Graduanda em Bacharelado em Relações Internacionais pela Universidade Federal de Santa Maria. E-mail: ; ${ }^{2}$ Professor de Filosofia do Instituto Federal de Educação, Ciência e Tecnologia do Amapá e Líder do Grupo de Pesquisa em Religiosidades Aplicadas às Humanidades.. ${ }^{3}$ Graduada em Bacharelado em Comunicação Social - habilitação em Publicidade e Propaganda pela Faculdade SEAMA e Técnica em Comunicação Social do Grupo de Pesquisa em Religiosidades Aplicadas Às Humanidades.

RESUMOO Sítio AP CA 18 é uma estrutura circular de grandes megalíticos, com 30 metros de diâmetros, a pesquisa da área, deu-se através do Grupo de Pesquisa em Religiosidade Aplicada as Humanidades (GPHRUM), com viés antropológico, da significação dos megalíticos como estrutura para ritos indígenas, já que além das estruturas megalíticas, há abrigos funerários, e diversos sítios com caráter votivo, posteriormente transformando-se em uma pesquisa mineralógica da área. A escolha da utilização de rochas graníticas está associada a propriedades minerais específicas e a características geológicas e minerais da região onde se encontra o sítio, tal trabalho visa à compreensão da natureza do local, em função das estruturas megalíticas e a identificação da presença mineral na região.

Palavras-chave: Caracterização mineral, Sítio AP CA 18, Geologia.

ABSTRACT:-The site AP CA 18 is a circular structure of large megalithic, with 30 meters in diameter, the research area, there was, through the Research Group on Religiosity Applied Humanities ( GPHRUM ) with anthropological bias of significance megalithic as the structure for indigenous rites, since beyond megalithic structures, there funeral shelters, and several sites with votive character, subsequently turning into a mineralogical search area. The choice of using granitic rocks is associated with specific mineral properties and geological and mineral characteristics of the region where the site, such work is aimed at understanding the site's nature, according to megalithic structures and the identification of mineral presence in the region.
\end{abstract}

Keywords: Mineral Characterization, Site AP 18 CA, Geology

\section{INTRODUÇÃO}

O sítio Arqueológico da Etnia Cunani é um zigurate às margens do Rio Rêgo Grande, que dista aproximadamente $14 \mathrm{~km}$ da sede do município de Calçoene no setentrião brasileiro. Ao se chegar ao local, observa-se a vasta planície e se percebe como os indígenas cunani realizaram tal feito, provavelmente com o objetivo de cultuar seus mortos e seus deuses, e a partir daí uma série de curiosidades se elencam.

A construção megalítica principal é formada por uma cripta onde no seu interior os jarros, bacias e vasos com restos mortais eram depositados após as cerimônias fúnebres e acima do recinto, fora construído um relógio solar que marca ainda hoje com precisão os solstícios.

Como uma civilização que não havia desenvolvido sua escrita conseguiu tal façanha de engenharia? Sem a escrita a anotação algébrica e geométrica se perde com a memória e a matemática toda escapa da precisão. Como foi possível uma astronomia invejável? Outro elemento que intriga é o fato dos cunani serem nômades. Assim, houve uma escolha a partir de conhecimentos que envolvem a geografia local para o levantamento do monumento principal e dos demais espalhados pela planície.

A chamada 'cabeça do cavalo' na verdade é uma representação do crânio humano. Provavelmente, o orifício que representa o olho e por onde se observa os solstícios, metaforicamente seja representação do desejo humano de contemplação da existência e elevação do espírito, acentuando a transcendência. É pouco provável que os indígenas cunani conhecessem o cavalo, pois o animal só chegou ao Brasil com o colonizador.

Dados como estes sobre o 'Stonehenge do Amapá' despertaram curiosidade epistemológica nos membros do GPRHUM que passaram a visitar frequentemente o local e desenvolver a análise mineralógica dos megalíticos. 


\section{CARACTERIZAÇÃO MINERAL}

O Sítio AP CA 18 é uma estrutura circular de grandes megalíticos, com 30 metros de diâmetro, localizado no município de Calçoene, estado do Amapá, o Projeto de Investigação Arqueológica na Bacia do Rio Calçoene foi financiado pelo Governo do Estado do Amapá e teve início em 2005. A partir do referido ano, um projeto de pesquisa foi desenvolvido no Instituto de Pesquisas Científicas e Tecnológicas do Estado do Amapá (IEPA) tendo como um dos objetivos levantar dados para a análise dos fenômenos arqueológicos. Os sítios arqueológicos formados por conjuntos de blocos de rocha foram referenciados na bibliografia para o Estado do Amapá já no final do século XIX, quando Emílio Goeldi realizou uma expedição ao Rio Cunani (Goeldi, 1905), porção norte do Estado. A teoria de povoamento mais clássica é sobre um povo ameríndio originário da zona caribenha que teria se instalado na fase Arnã antes de serem expulsos em uma segunda onda migratória, na fase Aristé (Cabral e Saldanha, 2008).

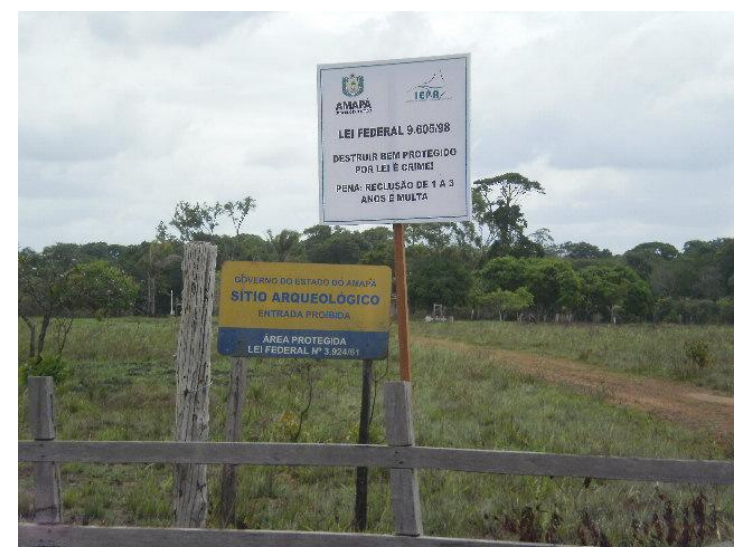

Figura 1 - Entrada do Sítio AP CA 18 (Fonte: GPRHUM)

Estas estruturas arqueológicas são conhecidas hoje ao longo de uma faixa de terra na porção Norte do Amapá, entre a linha de costa e as porções de terra firme no interior, na região de campos (Silveira, 1998). Os sítios são formados por conjuntos de blocos de rocha granítica, de variados tamanhos e organizados em diversas composições. Muitos blocos têm claras evidências de formatação, como lascamentos nas bordas, indício de preocupações com a forma das peças, mas há também blocos sem estas cicatrizes. A quantidade de blocos usados na construção das estruturas megalíticas é variável: há estruturas formadas por menos de dez blocos, enquanto outras passam de uma centena. A escolha da utilização de rochas graníticas está associada a propriedades minerais específicas e a características geológicas e minerais da região onde se encontra o sítio, tal trabalho visa a compreensão da natureza do local, em função das estruturas megalíticas e a identificação da presença mineral na região.

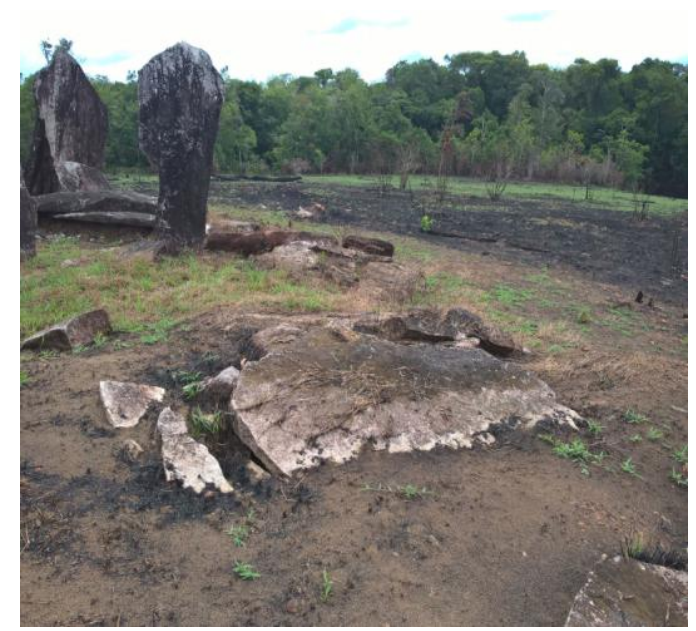

Figura 2 - Megalíticos

(Fonte: Instituto de Pesquisas Científicas e Tecnológicas do Estado do Amapá) 


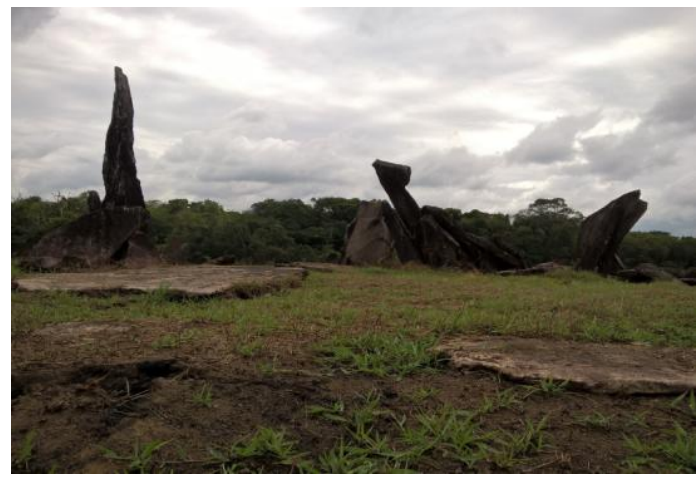

Figura 3 - Blocos megalíticos (Fonte: GPRHUM)

A pesquisa ora realizada baseou-se na obtenção de informações bibliográficas sobre os recursos minerais, a geologia regional e local, e sobre o meio ambiente no município de Calçoene, mais propriamente na área do sítio arqueológico AP CA 18. Como também, de importância relevante, utilizou-se o Relatório de Controle Ambiental do empreendimento. Junto às informações, tiveram ênfase os temas: Geologia geral do estado do Amapá, Geologia local do município de Calçoene e Características minerais presentes.

Considerando a sequência de eventos que determinaram esta pesquisa, têm-se os itens abaixo enumerados: Revisão bibliográfica das informações sobre a geologia regional e local e o tipo mineral presente na área, Coleta de informações acerca, Busca de informações junto ao DNPM e IEPA em relatórios técnicos, Visita de campo para coleta de amostras, Compilação de dados em texto e mapas, Avaliação e análise dos dados obtidos e Divulgação dos resultados em material científico.

\subsection{Localização e Acesso a Área}

A área em estudo refere-se ao sítio arqueológico AP-CA-18, no município de Calçoene, Estado do Amapá, distante cerca de 377 km da capital Macapá, via BR-156, na latitude de +2 graus 37' (hemisfério Norte). Calçoene é um dos 16 municípios do Estado do Amapá, situado na região nordeste do Estado, é um município de grande área, porém com uma população pequena, por volta de sete mil habitantes, sendo 5000 de acordo com o IBGE (2000), na área urbana.

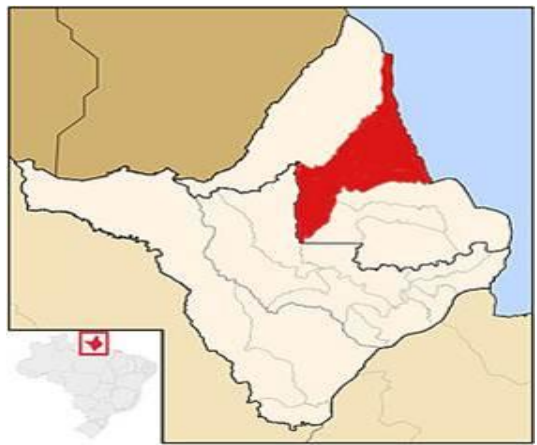

Figura 4 - Mapa de localização do município de Calçoene Fonte: Instituto de Pesquisas Científicas e Tecnológicas do Estado do Amapá

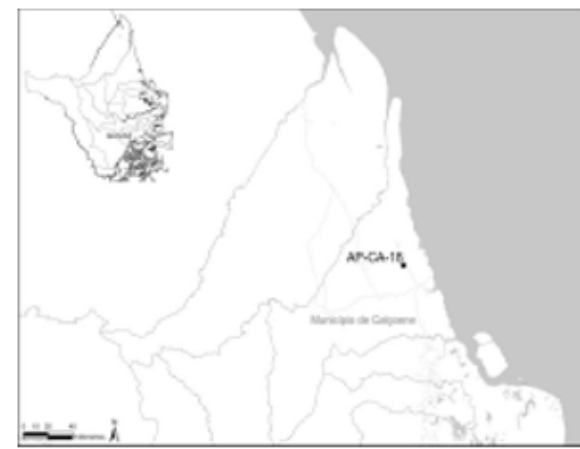

Figura 5 - Localização do sítio arqueológico AP-CA-18

Fonte: Cabral \& Saldanha 


\subsection{Geologia Regional}

Lima (1991) caracteriza a geologia do Estado do Amapá em quatro unidades geotectônicas distintas: núcleos preservados do pré-cambriano, cinturão de cisalhamento pré-cambriano, sedimentos homoclinais paleozóicos e sedimentos tabulares meso-cenozóicos. O Instituto de Pesquisas Científicas e Tecnológicas do Estado do Amapá (2002) apresenta um arcabouço geológico simplificado para o Estado do Amapá, caracterizado por duas unidades geotectônicas distintas: a) crosta antiga, retrabalhada ou não e; b) coberturas plataformais.

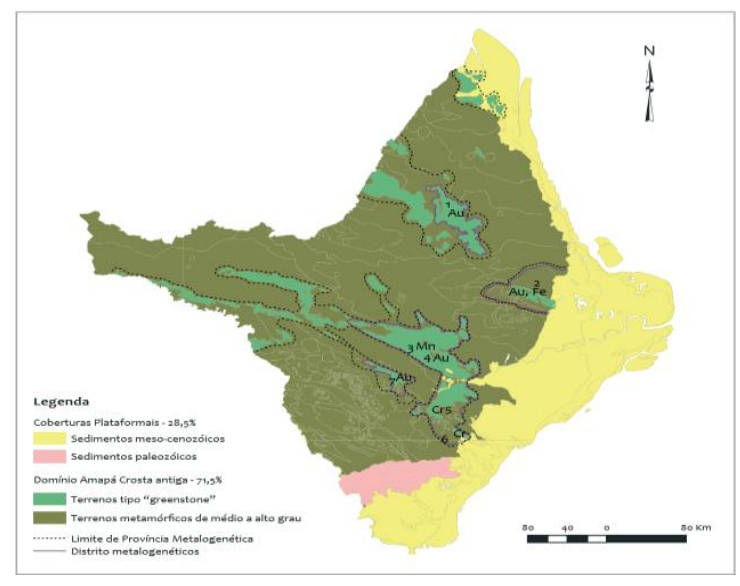

Figura 6 - Arcabouço geotectônico e distritos metalogenéticos do Amapá Fonte: Instituto de Pesquisas Científicas e Tecnológicas do Estado do Amapá

O estado do Amapá possui, como representado no mapa, distritos metalogenéticos, que correspondem a: 1 Lourenço (Au), 2 - Tartarugalzinho (Au), 3 - Serra do Navio (Mn), 4 - Serra do Navio/Vila Nova (Au), 5 Bacuri (Cr), 6 - Igarapé do Breu (Cr) e, 7 - Cupixi (Au).

No Estado do Amapá são identificados cinco compartimentos morfoestruturais, submetidos atualmente a retrabalhamento por processos erosivos (BOAVENTURA e NARITA, 1974). Essas unidades compreendem os Planaltos Residuais do Amapá; Planalto Rebaixado da Amazônia; Colinas do Amapá; Depressão Periférica do Norte do Pará e Planície Flúvio Marinha Macapá-Oiapoque. Lima et al. (1991) definiram uma nova classificação, também com cinco Unidades morfoestruturais, representadas pela Planície Costeira do Amapá; Planalto rebaixado da Amazônia; Planalto da Bacia da Amazônia; Planalto Dissecado Jari-Araguari e; Planalto Dissecado do Norte do Amapá.

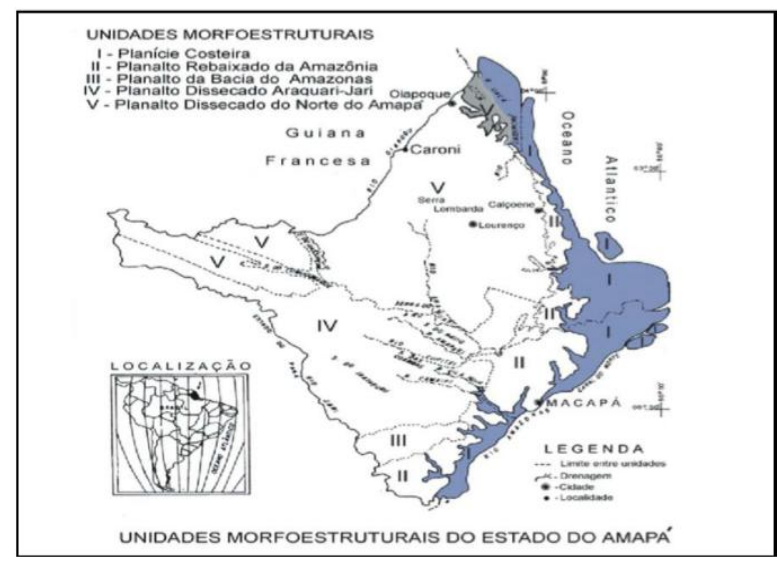

Figura 7 - Unidades Morfoestruturais do Estado do Amapá Fonte: Boaventura e Narita (1974)

\subsection{Geologia Local}

A região enquadra-se dentro do domínio da Zona Costeira do Amapá, que situa-se na posição predominantemente equatorial, estendendo-se por cerca de $750 \mathrm{~km}$, entre as desembocaduras dos Rios Oiapoque e Jarí. Nesta região, estão incluídas duas grandes áreas: o Setor Atlântico da Costa do Amapá e o Golfão Amazônico. De acordo com o GERCO do Amapá, a ZCA pode ser compartimentada em dois setores, devido à 
presença da foz do rio Araguari. O setor ao norte da foz do rio Araguari até o limite com a Guiana Francesa é designado como Setor Costeiro Oceânico ou Atlântico, abrangendo parte dos municípios de Oiapoque, Calçoene, Amapá, Pracuúba e Tartarugalzinho; e o setor situado entre os estuários Araguari e Jarí (limite com o Pará) é chamado de Setor Costeiro Estuarino ou Amazônico, abrangendo parte dos municípios de Cutias, Itaubal do Piririm, Macapá, Santana, Mazagão e Vitória do Jarí (Torres e El-Robrini).

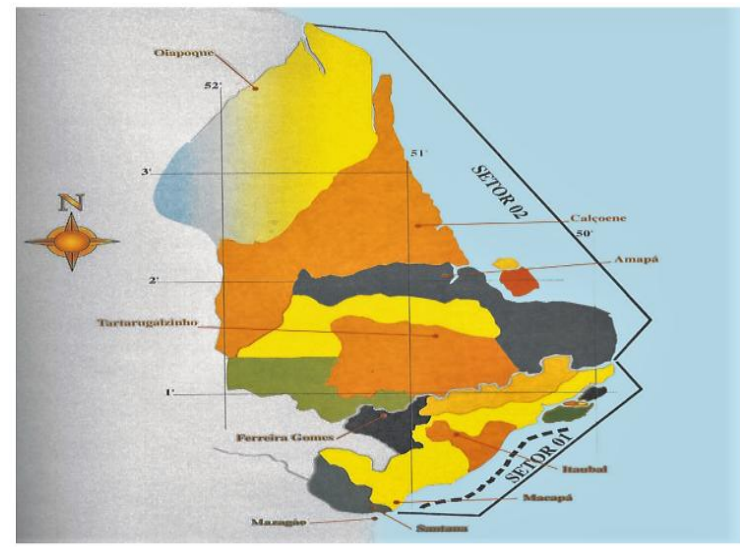

Figura 8 - Mapa de localização da Zona Costeira do Estado do Amapá (ZCA): Setor 1. Amazônico Setor 2. AtlânticoFonte: IEPA

A área de pesquisa situa-se em uma região extremamente dinâmica do ponto de vista ambiental. Durante o Holoceno, a costa atlântica do Amapá sofreu mudanças dramáticas causadas por diferentes fatores, como o sistema de dispersão do rio Amazonas e a ação de macro-marés (Silveira, 1998, apud Cabral \& Saldanha, 2008).

Dividindo-se em três grandes zonas ecológicas, ao longo da costa são encontrados manguezais crescendo sobre cabos lamosos. Associados com a floresta de mangue existem porções de campos planos que crescem sobre sedimentos Holocênicos, podendo ser diariamente alagadas devido à ação das marés. Atrás dessa primeira zona são encontrados campos que crescem sobre terrenos do Terciário, inundados anualmente durante a estação das chuvas. Estes campos planos e baixos são interrompidos por florestas de galeria ou por áreas naturalmente altas, conhecida como "ilhas". Estas são as únicas porções de terra que escapam do alagamento durante as chuvas. A maioria dos sítios até agora conhecidos na área é encontrada no topo destas "ilhas" (Cabral \& Saldanha, 2008).

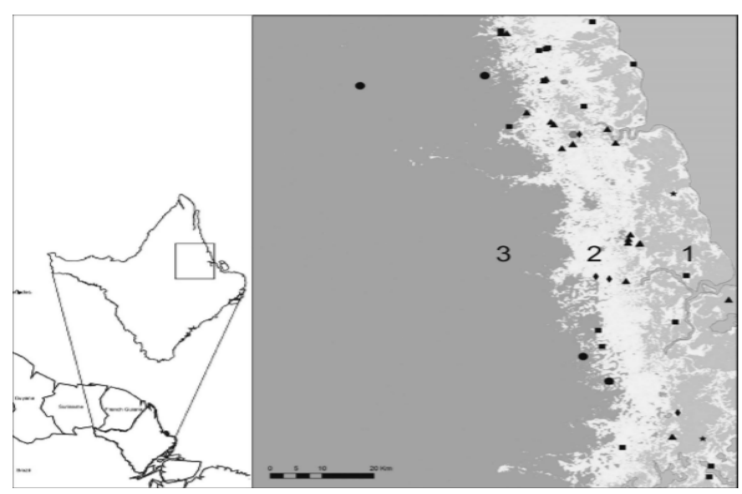

Figura 9 - Distribuição dos sítios arqueológicos sobre as três zonas ecológicas: 1) manguezais; 2) campos; e 3) terra firme.Fonte: Cabral \& Saldanha

Uma Entidade Tectônica, segundo mapa do CPRM Geológico do Amapá, com Orógenos Proterozóicos/Arcos Magmáticos e Bacias Relacionadas que apresenta Suíte Tonalítica a Granítica, Calcialcalina com Rochas Máficas Relíquias de Rochas Supracrustais Associadas, no Domínio Amapá como Domínio Tectono-Estrutural, datado do Éon Proterozóico, da Era Paleoprterozóica,que é subdividida em quatro períodos: Sideriano, Riaciano, Orosiriano e Estateriano. Tal entidade tectônica apresenta-se do período Riaciano, que se extende de 2.300 à 2.050 milhões de anos. No Riaciano teve-se início uma série de colisões entre placas tectônicas, comprimindo as bacias sedimentares geradas no Período Sideriano, num processo chamado orogenia. Essas orogenias se instalam em praticamente todos os continentes, como por exemplo:

DOI: 10.9790/0837-2107082834 www.iosrjournals.org $\quad 32 \mid$ Page


Orogenias Hudsoniana e Penokeana, na América do Norte; Svecokareliana, no Escudo Báltico; Eburneana, na África e Transamazônica, na América do Sul (CPRM).

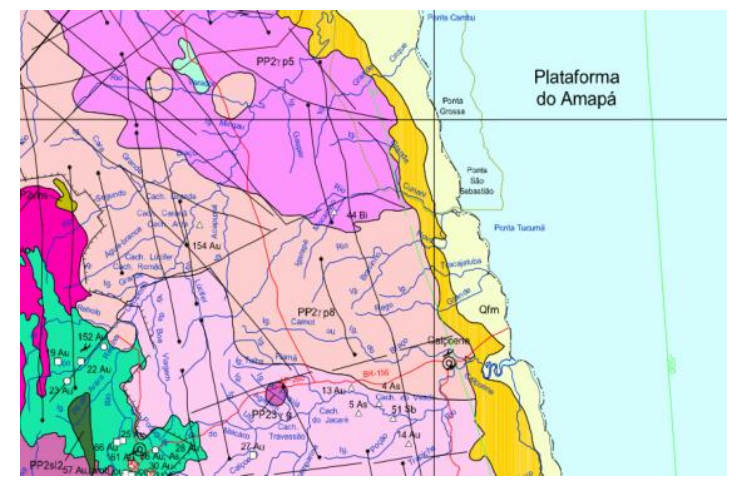

Figura 10 - Mapa Geológico do estado do AmapáFonte: CPRM

\subsection{O Trabalho de Campo}

A visita de campo efetuou-se em três momentos, em Julho de 2012 e em Maio de 2014, decorrente de visitas dos membros do GPRHUM ao local, onde no segundo momento houve uma visita maior à área do Sítio, incluindo além do principal, o sítio Garrafinha. Por fim, material de rocha megalítica estudado no Laboratório de Mineração do IFAP.Em Dezembro de 2015, a visita foi para coleta de pequenos blocos de rocha granítica para análise mineralógica e comparação com a bibliográfica consultada para pesquisa.

Durante o trabalho de campo utilizou-se martelo geológico, saco de amostras, e fez-se a coleta com uma distribuição uniforme da área de modo que houvesse uma boa representatividade.

\subsubsection{Caracterização Petrográfica}

Nas regiões com áreas mais altas, há embasamento granítico que se encontra exposto. Os indígenas da fase Aristé utilizaram-se do granito, uma rocha ígnea félsica, com dureza variável entre 6 e 7 na escala Mohs, e que possui a seguinte composição química: Quartzo (SiO2), Feldspato (KAlSi3O8) e as Micas, sendo mais comum a Biotita (K2 (Mg, Al, Fe)6 (Si2, Al)8 O20 (OH)4). Trata-se de uma rocha granulométrica, de estrutura compacta pouco porosa.

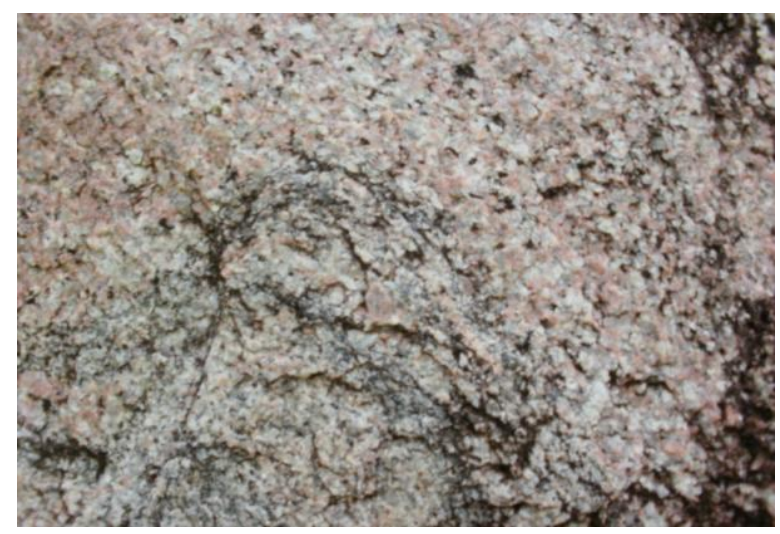

Figura 11 - Rocha Granítica

As rochas coletadas como amostra foram analisadas com auxilio de lupa de aumento (com aumento de até $40 \mathrm{x}$ ) e a olho nu, em 05 de junho de 2014 no Laboratório de Mineração do Instituto Federal do Amapá, Campus Macapá. Nessas análises identificou-se a seguinte composição:

- Análise a olho nu: foram detectados predominantemente mica biotita e quartzo.

- Análise com auxilio da lupa de aumento: foram encontrados feldspato, quartzo, mica biotita e muscovita. A estimativa é que $70 \%$ dos minerais sejam biotita e quartzo. 


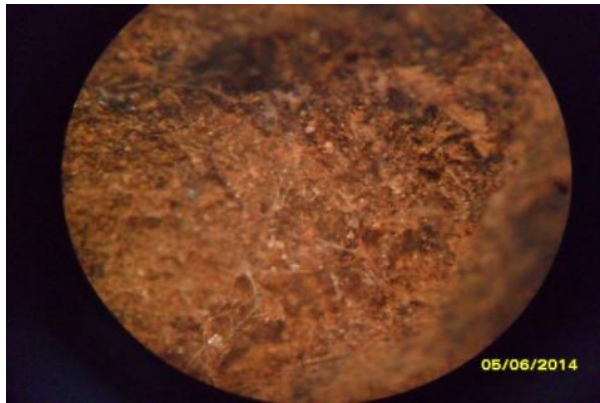

Figura 12 - Análise com lupa de aumento

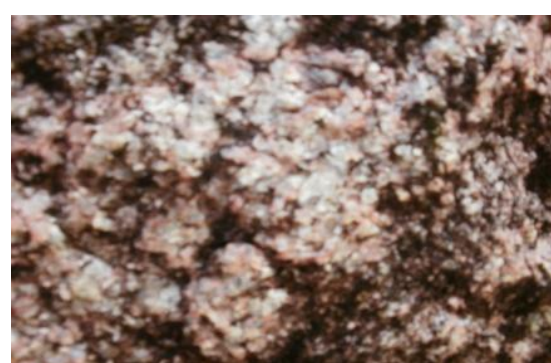

Figura 13 - Cristais da rocha granítica

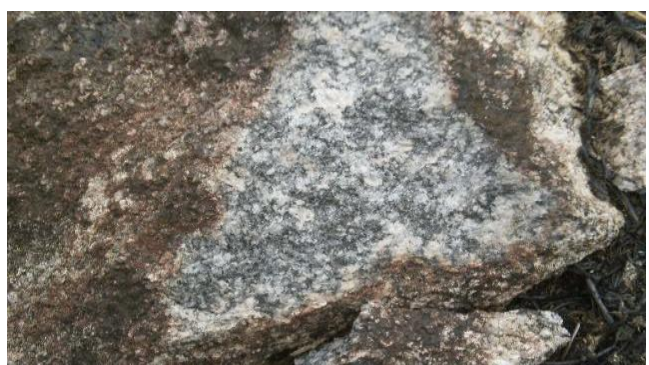

Figura 14 - Amostra de bloco de rocha granítica

III.

\section{CONSIDERAÇÕES FINAIS}

A apresentação de tal trabalho de pesquisa possuiu como intuito a consolidação do aprendizado teórico e prático através da correlação existente entre os conteúdos estudados durante o curso de técnico em mineração, evidenciando-se os componentes curriculares: mineralogia, geologia geral e meio ambiente e segurança no trabalho, além da análise da Filosofia da Religião como tema principal do Grupo de Pesquisa em Religiosidades Aplicadas às Humanidades. Traços de superticiosidades e panteísmo foram percebidos nos cultos oferecidos no Sítio AP CA 18, pois o culto aos mortos e as oferendas, tão antigos em várias culturas espalhadas pelo planeta, também aconteciam no Stonehenge amapaense.

A partir de tais conhecimentos identificou-se, a escolha das rochas graníticas, pelo referido povo, para a construção e disposição dos megalíticos, mesmo baseadas em conhecimento empírico, revelou-se correta, utilizando de uma rocha com fraturamento conveniente de modo que alguns blocos se mantivessem sem lascamentos, resistente ao tempo, com dureza entre 6 e 7 na escala Mohs, mas com uma estrutura cristalina que fosse permissiva ao talhamento quando necessário. Escolha justificada pela presença associada a propriedades minerais específicas e a características geológicas e minerais da região.

Por fim, o caráter interdisciplinar do GPRHUM fora acentuado nesta experiência, dando a devida relevância ao resgate cultural do norte do Amapá.

\section{REFERENCIAS}

[1] CABRAL, Mariana Petry \& SALDANHA, João Darcy de Moura. Um Sítio, múltiplas interpretações: o caso do chamado "Stonehenge do Amapá". IN: Revista Arqueologia Pública, UNICAMP, São Paulo, n. 3, 2008, p. 07-14

[2] BOAVENTURA, F. M. C ; NARITA, C. Geomorfologia da Folha NA/NB-22-Macapá. In: PROJETO RADAM. Folha NA/NB-22-Macapá: geologia, geomorfologia, solos, vegetação e uso potencial da terra. Rio de Janeiro : DNPM, 1974. (Levantamento dos Recursos Naturais, v.6)

[3] GOELDI, E. 1905. Excavações Archeologicas em 1895. $1^{\text {a }}$ parte: As Cavernas Funerarias Atificiaes dos Indios Hoje Extinctos no Rio Cunany (Goanany) e sua Ceramica. Belém, Série Memórias do Museu Goeldi

[4] IBGE. Censo Demográfico. São Paulo, IBGE. 2000.

[5] . Mapa Geológico do Estado do Amapá. Macapá, 2004.

[6] LIMA, M. I. C.; BEZERRA, P. E. L.; ARAÚJO, H. J. T. Sistematização da geologia do Estado do Amapá. In: SIMPÓSIO DE GEOLOGIA DA AMAZÔNIA, 3., 1991, Belém, PA, AnaisBelém, PA: SBG, p. 322-335.

[7] LOPESNIMUENDAJÚ, C. 2000. Cartas do Sertão: de Curt Nimuendajú para Carlos Estevão de Oliveira. Lisboa, Assírio \& Alvim/ Museu Nacional de Etnologia.

[8] SILVEIRA, O.F.M. 1998. A Planície Costeira do Amapá: Dinâmica de Ambiente Costeiro Influenciado por Grandes Fontes Fluviais Quaternárias. Tese de Doutoramento. Belém, UFPA. 